\title{
Digging your own grave: OSL signatures in experimental graves
}

\author{
Justine Kemp \\ Corresponding author: Australian Rivers Institute, Griffith University, Nathan, Queensland, Australia 4111 \\ j.kemp@griffith.edu.au. Ph: +61 737354820 \\ Timothy J. Pietsch
}

Australian Rivers Institute, Griffith University, Nathan, Queensland, Australia 4111; t.pietsch@griffith.edu.au Jon Olley

Australian Rivers Institute, Griffith University, Nathan, Queensland, Australia 4111; j.olley@griffith.edu.au

\begin{abstract}
Excavation of mock graves in sediments of aeolian and fluvial origin were conducted to test the bleaching efficiency of grave digging in materials that commonly host ancient burials in Australia. Grave-size pits were dug into Pleistocene aeolian sediments at Willandra Lakes, and younger fluvial sediments on the Lachlan River, backfilled, and re-excavated. Samples for optical dating were taken from sediment infilling the mock graves and from the adjacent, undisturbed substrate, and analysed using the SAR protocol applied to single quartz grains. The resulting equivalent dose $\left(D_{e}\right)$ distributions revealed that $\leq 1 \%$ of grains had been fully zeroed in both settings, and an additional 1-6\% of poorly bleached grains were apparent in the fluvial sediments. Insufficient and heterogeneous bleaching of sediments during excavation and backfilling produced a decrease in the central dose of between 3 and $6 \mathrm{~Gy}$, and an increase in over-dispersion values of between 5 and $10 \%$. These differences were insufficient to clearly distinguish the disturbance event from the effects of bioturbation, biological mixing, or other sources of $\mathrm{D}_{\mathrm{e}}$ variation. The use of the minimum age model substantially over-estimated the burial age (zero years) in both depositional environments, with the degree of over-estimation increasing with the age of the host sediments. These results suggest that OSL techniques will not produce accurate ages for grave infill in a number of forensic and archaeological settings.
\end{abstract}


Further study of the bleaching susceptibility of grains within grave infills, as well as the effectiveness of gravedigging as a bleaching mechanism is required. In other archaeological and geomorphological applications of OSL dating we recommend routine checks on the effective zeroing of sediments in modern equivalent situations.

Keywords -luminescence dating; quartz OSL; sunlight bleaching; graves; cemeteries; forensic archaeology

\section{Introduction}

Over the last decade, optically stimulated luminescence (OSL) has revolutionised the dating of archaeological sites (e.g. Jacobs and Roberts, 2007, Cochrane et al., 2013). Recent innovative applications include the OSL dating of agricultural terraces (Beckers et al., 2013), irrigation canals and ditches (Berger et al., 2009), hearths (Rhodes, 2010), cement mortar in ancient buildings (Feathers et al., 2008), and building pits (Sanjurjo-Sánchez and Mato, 2013). . Single grain OSL has also been used in the dating of ancient human fossils and burials, where sediments infilling the grave pit approximate a direct age for the fossil itself because the luminescence signal is bleached or "zeroed" by a few seconds of exposure to sunlight (Aitken, 1998; Wintle, 1997). The technique has become important in Australian archaeology where the timing of the earliest human burials is close to, or exceeds, the limits of practicable radiocarbon dating, and a closed system for uranium-series dating is difficult to demonstrate (Thorne et al., 1999; Bowler et al., 2003; Olley et al., 2006; Grün et al., 2011). In these ancient archaeological settings it is important to establish the validity of luminescence techniques.

Unless sedimentation is particularly rapid, grave sites become subject to soil development and bioturbation following excavation and closure. This process may be continuous or episodic, particularly where graves are re-exposed to the surface after prolonged or recent erosion. Graves are often dug into sediments that are older than the occupation layer, and optical dating of samples adjacent to grave sites then represents the age of the landform. The identification of the excavation age is based on the assumption that 
grave infill sediments are uniformly zeroed prior to grave closure; or, if they are not, that a population of grains that were zeroed during the digging and closure of the grave may be distinguished from grains that retain a residual equivalent dose using the "minimum age model", or another statistical measure arranged to distinguish the most recent depositional event (Galbraith et al., 1999; Galbraith, 2005; Olley et al., 2006). To our knowledge, the assumption that grave digging produces sufficient numbers of zeroed grains to permit clear identification of a burial age has not been tested in Australian conditions or elsewhere. This paper examines the bleaching efficiency of mock-grave excavations in two depositional environments that are commonly host to ancient burials in southeastern Australia.

\section{Materials and methods}

Sites

Lake Gogolo (GG 16; $33.548{ }^{\circ} \mathrm{S}, 143.158^{\circ} \mathrm{E} ; 75 \mathrm{~m}$ AHD) is an ancient overflow lake near the southern margin of Lake Garnpung, the largest lake basin within the Willandra Lakes World Heritage Area. The lakes have been dry since the LGM and significant deflation of the aeolian lunette at GG 16 has exposed much of the underlying sediment, including a rich archaeological record that includes 35 human burials, hearths and other artefacts dating between 15.5 and $22 \mathrm{ka}$ (Webb 1989; Johnston et al., 2003). The first mock grave, Polly 1, was excavated in aeolian sands stratigraphically underlying the sedimentary unit containing these human fossils. Rates of sandy lunette deposition over the grave site and its subsequent deflation have been sufficiently rapid to preclude soil development. A view of the sediments is given in Fig. 1.

The second site, Polly 2, $\left(33.361^{\circ} \mathrm{S}, 147.637^{\circ} \mathrm{E} ; 220 \mathrm{~m}\right.$ AHD) was excavated in a fluvial levee in the middle reaches of the Lachlan River, $480 \mathrm{~km}$ upstream. The site is $1.2 \mathrm{~km} \mathrm{~S}$ of the modern Lachlan and adjacent to a palaeochannel of the Ulgutherie Palaeochannel System, which was the feeder channel to the Willandra Lakes during the Pleistocene. OSL ages on fluvial sands $1 \mathrm{~km}$ upstream suggest that active sedimentation of the floodplain occurred between 21 and $<25 \mathrm{ka}$ although the channel may have been 
abandoned more recently (Kemp and Rhodes, 2010). Eucalyptus camaldulensis (river red gum) open woodland provided a canopy cover of $\sim 20 \%$.

[Figure 1]

Experimental grave digging

A mock grave $110 \mathrm{~cm} \mathrm{~L} \mathrm{x} 50 \mathrm{~cm} \mathrm{~W} \mathrm{x} \mathrm{60-70} \mathrm{cm} \mathrm{D} \mathrm{was} \mathrm{excavated} \mathrm{at} \mathrm{each} \mathrm{location.} \mathrm{The} \mathrm{weather} \mathrm{on}$ both days in late July was partly cloudy. A moderately strong wind during the excavation of Polly 1 produced active sand transport across and into the grave. Polly 1 sediments were weakly cemented, reddish brown, well sorted fine and medium sands. The grave pit was dug by hand and archaeological trowel over 20 min and the spoil heap left for $4 \mathrm{~h}$ (1040-1500), during which time ground temperatures were sufficiently high to dry the top half of the spoil heap. The pit was then backfilled with sediment from the spoil heap and compressed by hand. Ten minutes later the pit was re-excavated with a trench cut transverse to the long axis, exposing previously undisturbed sediment, the pit wall and pit infill. At Polly 2, excavated sediments were weakly cemented pale reddish brown fine sand showing significant soil development, fining at $20 \mathrm{~cm}$ to moderately cemented silty fine sand. The excavation was accomplished by spade over $1 \mathrm{hr}$, the spoil heap left for $30 \mathrm{~min}$ (1000-1130), then infilled, compressed, and immediately re-excavated as for Polly 1 . The largest clods in the spoil heap were $<3 \mathrm{~cm}$ diameter. Samples were collected in the re-excavated pits from the disturbed and undisturbed sediments using stainless steel tubes hammered into the face (Fig. 1). Approximately $1 \mathrm{~kg}$ of sediment was collected from the undisturbed substrate for determination of the environmental dose rates and moisture contents.

\section{Dating procedures}

Sample tubes were opened under subdued red-light and sediment from the centre of each tube was extracted for processing. Sample processing followed standard procedures (e.g. Aitken, 1998), with 
treatments applied to remove contaminant clays, carbonates, feldspars, organics, heavy minerals and acid soluble fluorides. The samples were etched with $48 \%$ hydrofluoric acid. Single-grain equivalent dose $\left(\mathrm{D}_{\mathrm{e}}\right)$ values were determined using the modified single aliquot-regenerative dose (SAR) protocol of Olley et al. (2004) and Risø instrumentation described therein. This method used a $240^{\circ} \mathrm{C} / 10 \mathrm{~s}$ preheat for the Natural and Regenerative doses, a $160^{\circ} \mathrm{C}$ cutheat for the 1 Gy Test Doses, a $125^{\circ} / 40$ s IR 'wash' ( $\sim 870 \mathrm{~nm}, 135$ $\mathrm{mWcm}{ }^{2}$ applied to all 100 grains on each disc simultaneously) prior to all single grain OSL measurements $\left(125^{\circ} / 1 \mathrm{~s} /\right.$ green $\left(532 \mathrm{~nm} / \sim 50 \mathrm{Wcm}^{2}\right)$ laser $)$. The acceptance / rejection criteria of Pietsch (2009) and Pietsch et al. (2013) were used. Grains were rejected if they: did not produce a measurable (i.e. $>3$ standard deviations above background) OSL signal in response to the first test dose; had OSL decay curves that did not reach background after $1 \mathrm{~s}$ of laser stimulation; had growth curves with observable recuperation indicated by zero dose points with a sensitivity-corrected OSL not within $1 \sigma$ of zero; had recycling ratios not consistent with unity at $1 \sigma$; had regeneration points that either had individual uncertainties $>15 \%$ or lay more than $2 \sigma$ above or below the fitted curve; or had Test Dose signals associated with the first and second regenerative doses that varied in sensitivity from the first Test Dose signal (associated with the Natural Dose) by more than $20 \%$.

The age modelling approach of Galbraith and co-workers (Galbraith and Laslett, 1993; Galbraith et al., 1999; Roberts et al., 2000) was used to characterise the population of single grain $\mathrm{D}_{\mathrm{e}}$ values. First the Central Age Model (CAM) was used to determine the central age dose $\left(\mathrm{D}_{\mathrm{e}}\right)$ and over-dispersion $\left(\sigma_{\mathrm{d}}\right)$ for each sample, with $\sigma_{\mathrm{d}}$ representing the degree of spread in the data beyond that which can be explained by known sources of uncertainty (i.e. measurement uncertainty on each individual single grain $D_{\mathrm{e}}$ ) (Galbraith et al., 1999). Non-zero $\sigma_{d}$ values are almost universally found for single grain dose distributions with the greatest component of this traditionally attributed to heterogeneous bleaching (e.g. Olley et al., 2004). The central age dose, as calculated using the CAM, is a weighted mean of the dose distribution calculated from individual $\operatorname{logged} \mathrm{D}_{\mathrm{e}}$ values that are weighted by the reciprocal of their variance. A three parameter Minimum Age Model (MAM) was applied to identify the most recent depositional event. The MAM takes the median of a 
truncated normal distribution fitted to the lowest $D_{\mathrm{e}}$ component of the dose distribution in order to distinguish grains effectively zeroed at deposition from apparently older grains that have retained a residual signal from earlier depositional episodes (Galbraith et al., 1999). Here, we used a $\sigma_{\mathrm{d}}$ of $15 \%$ for this lowest $D_{\mathrm{e}}$ component when applying the MAM. This value was assumed to account for sources of spread in addition to heterogenous bleaching and therefore present even in any fully bleached component, including the effects of $\beta$-dose heterogeneity (Nathan et al. 2003).

The field dose rates were determined by laboratory analysis of the radionuclide concentrations in samples taken adjacent to the optical dating samples in the substrate sediments. These were analysed by highresolution gamma spectrometry for ${ }^{238} \mathrm{U},{ }^{226 \mathrm{Ra}},{ }^{210} \mathrm{~Pb},{ }^{232} \mathrm{Th}$ (calculated as the weighted mean of ${ }^{228} \mathrm{Th}$ and ${ }^{228} \mathrm{Ra}$ ) and ${ }^{40} \mathrm{~K}$ concentrations (Murray et al., 1987); dose rates were calculated using the conversion factors of Stokes et al., (2003); $\beta$-attenuation factors were taken from Mejdahl (1979); cosmic dose rates were calculated from Prescott and Hutton (1994); the effective internal alpha dose rate (applied to all samples) has been estimated using an alpha-efficiency ' $a$ ' value of $0.04 \pm 0.02$, as measured previously for quartz grains from Willandra Lakes (Bowler et al., 2003). We have assumed that the measured water contents, which were assigned uncertainties of $\pm 5 \%$, are representative of those pertaining to the full period of sample burial.

\section{Results}

Re-excavation of the mock graves in both locations revealed grave boundaries that were clearly visible against the undisturbed sediments (Fig. 1). Measured concentrations of ${ }^{238} \mathrm{U}$ activity were within analytical uncertainties of ${ }^{226} \mathrm{Ra}($ at $1 \sigma)$ and ${ }^{210} \mathrm{~Pb}($ at $2 \sigma)$ (Tab. 1) in both samples, consistent with secular equilibrium. The dose rate was calculated as $0.89 \pm 0.07 \mathrm{~Gy} \mathrm{ka}^{-1} \mathrm{yr}^{-1}$ in the aeolian dune (Polly 1 ) and $3.09 \pm 0.17 \mathrm{~Gy} \mathrm{ka}^{-1} \mathrm{yr}^{-1}$ in the fluvial levee (Polly 2) (Tab. 1). For each sample 500 grains were measured. The proportion of grains yielding $\mathrm{D}_{\mathrm{e}}$ estimates ranged between 11 and $28 \%$ (Fig. 2). At Polly $1, \mathrm{D}_{\mathrm{e}}$ values in the undisturbed sample ranged from 5.6 to $80 \mathrm{~Gy}$ with a central $\mathrm{D}_{\mathrm{e}}$ calculated using the Central Age Model of 36.7 \pm 1.1 Gy (Fig. 3a, Tab. 2; Galbraith et al., 1999). This compared with $\mathrm{D}_{\mathrm{e}}$ values for the grave infill 
samples ranging from 0 to $61 \mathrm{~Gy}$ with a central age $\left(\mathrm{D}_{\mathrm{e}}\right)$ averaging $30.7 \pm 1.0 \mathrm{~Gy}$ (Fig. 3b, 3c). This indicates a decrease in the central age between disturbed and undisturbed samples of $5.8 \mathrm{~Gy}(16 \%)$. One grain, representing $<1 \%$ of grains with acceptable dose characteristics in the upper infill sample at Polly 1 [PGG17] was effectively zero in age, while the lower infill sample [PGG40] produced no zero-age grains and a single grain $(1.1 \%)$ with an apparent sample age of $<100 \mathrm{yr}$ (Fig. 3d). Over-dispersion values increased from 34\% in the substrate to $>44 \%$ in the disturbed samples. This spread of natural doses is broad for aeolian sediments, which have been found to bleach uniformly at the time of deposition with values for over-dispersion of $<20 \%$ (Olley et al., 2004; Duller, 2008). Excessive over-dispersion may indicate that bioturbation has operated over extended periods and depths within the GG 16 lunette. Erosion of the dune may have begun several thousand years ago, following a similar path to Lake Mungo and exposing the deeper sediments to biological mixing (Fitzsimmons et al., 2014). This may explain the small number of low-dose grains, approximately $1.5 \%$ of the sample. In addition, variations in the radiation field are more apparent in low dose environments and may have contributed to high over-dispersion, particularly if radioactive elements have been concentrated within iron-rich coatings on individual grains (Roberts and Plater 1999; Olley et al., 2006; Lomax et al., 2007). In such situations, the Central Age Model would most accurately determine the age of aeolian deposition. In combination with the calculated dose rate this gives an age of $41.1 \pm 3.3 \mathrm{ka}$. To identify a disturbance event such as a human burial, the Minimum Age Model normally would be applied to discount the effect of heterogeneously or insufficiently bleached grains. For comparative purposes, the MAM was applied to both infill and substrate samples. This yielded an age of $27.2 \pm 1.3 \mathrm{ka}$ for the undisturbed substrate compared to $29.1 \pm 2.8$ and $16.5 \pm 2.1$ ka for the infill (Tab. 2).

[Figure 2]

[Table 1]

[Table 2]

At Polly $2, D_{e}$ values in the undisturbed sample ranged from 0.9 to $26 \mathrm{~Gy}$ with a central age $\left(\mathrm{D}_{\mathrm{e}}\right)$ of 6.2 \pm 0.6 Gy (Fig. 4a, Tab. 2). The infill sample produced a range of 0.2 to $35 \mathrm{~Gy}$, with a central age of 
3.5 \pm 0.2 Gy (Fig. 4b, Tab. 2). At this site, excavation apparently reduced the central $\mathrm{D}_{\mathrm{e}}$ by $2.7 \mathrm{~Gy}(44 \%)$. Values for over-dispersion were $73 \%$ compared to $78 \%$ in the disturbed sample. The spread of $\mathrm{D}_{\mathrm{e}}$ values in the undisturbed sample is characteristic of fluvial sediments, which are poorly bleached at the time of deposition, and/or bioturbation, which will produce a spread such as that observed even for initially well bleached material (Olley et al., 1999). In the excavated sediment, one grain (0.7\%) was effectively zero age. A further $2 \%$ yielded apparent ages of $<150 \mathrm{yr}$, and $4 \%$ were $<250 \mathrm{yr}$. The Minimum Age Model yielded an age of $0.63 \pm 0.1 \mathrm{ka}$ for the undisturbed sample compared with $0.41 \pm 0.05 \mathrm{ka}$ for the infill. The use of unlogged $D_{e}$ values can be preferable for very young samples where individual $D_{e}$ estimates may be close to zero or negative (Arnold et al., 2009). In this case, the use of unlogged values in the MAM reduces the ages to $0.37 \pm 0.13$ and $0.12 \pm 0.07 \mathrm{ka}$, but the values are strongly affected by the inclusion of a single, nearly zeroed grain (Fig. 4c).

[Figure 3]

[Figure 4]

\section{Discussion}

In order to confidently identify the age of a grave site using single grain OSL, it is necessary to be able to recognise an unambiguous excavation signal produced by fully bleached grains during the excavation or grave closure. Zeroed grains (in modern graves) must be present in sufficient numbers to be distinguishable from the effects of contamination, bioturbation, or other mixing. The interpretation of small numbers of low dose grains has always been problematic, especially in situations that require use of the Minimum Age Model (Galbraith et al., 1999). The fluvial and the aeolian environments tested here produced complete zeroing of grains in $\sim 1 \%$ of the analysed sample and low doses in a further $1-6 \%$, levels that would be regarded by most analysts as outliers from the target bleaching event (e.g. Jacobs et al., 2006).

The presence of grains with lower $\mathrm{D}_{\mathrm{e}}$ values rains or a diagnostic change in the distribution of $\mathrm{D}_{\mathrm{e}}$ values compared with the adjacent undisturbed sedment may indicate disturbance associated with grave 
digging. Samples from Polly 1 did expose an offset of $5.8 \mathrm{~Gy}$ in the central age $\left(\mathrm{D}_{\mathrm{e}}\right)$ and a modest increase in values for over-dispersion. However, the broad dose distribution from the GG 16 lunette is a reminder that aeolian sediments are not always well behaved (see Duller et al., 2008). Comparison with the undisturbed substrate may be particularly problematic in archaeological sites, where, in general, sediments are more poorly sorted than those in unoccupied settings. Bruno et al. (2007) note that all archaeological sites contain some degree of mixing. The age of sediments in Polly 1 corresponds to the oldest human remains at Lake Mungo, $20 \mathrm{~km} \mathrm{SSW}$, and although there is no direct evidence for anthropogenic disturbance in our section, mixing of grains from different layers, possibly combined with variable microdosimetry, has made the task of isolating an excavation age at GG 16 more difficult. A clearer excavation signal exists in the fluvial sediments at Polly 2, with a peak in $\mathrm{D}_{\mathrm{e}}$ values read at $2.3 \mathrm{~Gy}$ (equivalent to $\sim 750 \mathrm{yr}$ ). Despite this, the Minimum Age Model applied to both substrate and infill samples identifies an age reduction of only $220 \mathrm{yr}$ (250 yr using the unlogged model), noting that substrate age probably represents the effects of bioturbation. While this might be sufficient evidence of disturbance, its timing would be overestimated by 400-750 yr depending on the age model selected. This is an unacceptably large error on recent sediments, especially for forensic investigations of recent interments. Over historical and archaeological timescales, additional mixing is likely to widen and skew any peak associated with the bleaching event. In addition, mixing may be enhanced in grave sites because disturbance accelerates soil development by increasing aeration and biotic activity, expediting root growth and water infiltration (Sojka, 1999). When removed from the effects of bioturbation by deep burial, the excavation signature may remain indistinguishable from bioturbation or the downward migration of younger grains.

Conditions for bleaching were ideal at both excavation sites, which are located at relatively low latitudes with abundant direct sunlight over 1-4 hours working on "bright" quartz sand that appears to act as reliable dosimeters when subjected to the usual tests. The lack of zeroed grains then requires explanation. The decrease in central $D_{e}$ values without an accompanying reduction in $D_{e}$ range at both sites suggests that grave digging produced insufficient bleaching of the sediments (sensu Ballarini et al., 2007), in which single grains experienced only partial loss of their trapped charge, as well as heterogeneous bleaching (Olley and 
Murray, 2002), where only a proportion of grains were zeroed by exposure. Shielding of grains on the spoil heap might explain heterogeneous bleaching at Polly 2, where the fluvial sediments were finer and more cemented at depth. On the other hand, digging proceeded more slowly and additions to the spoil heap became smaller as the degree of cementation increased. Some shielding of grains may also have occurred at Polly 1, but the loose aeolian sediments excavated by hand and trowel were more effectively scattered over the spoil heap. Expressed in absolute terms, Polly 1 experienced a larger reduction in $\mathrm{D}_{\mathrm{e}}$, which may reflect the less cohesive properties of aeolian sands.

Insufficient bleaching of the infill sediments is harder to explain, as it suggests an insufficient exposure time in sunlight exposed grains. The possibility of light attenuation caused by the accumulation of iron-rich coatings on the weathered sands of the lunette at Polly 1 may offer part of the explanation.

Bleaching experiments conducted by Lomax et al. (2007) in aeolian dune sediments from South Australia did reveal a reduction in bleaching efficiency caused by the presence of a weathering rind, such that complete zeroing time increased from $50 \mathrm{~s}$ in etched quartz grains to $120 \mathrm{~s}$ in quartz with iron-rich coatings preserved. Despite this, more than half of the bleaching in their experiment was accomplished by exposure to $5 \mathrm{~s}$ of sunlight in both etched and unetched samples. In the present case it is surprising that a larger bleaching signal was not recognisable in the conditions under which our experiment took place. Grain shielding will increase with the size of excavation clods or handfuls, which restricts sunlight to grains not exposed on its surface area. An intact clod with radius of $3 \mathrm{~cm}$ contains fewer than $3 \%$ of grains in its outer skin. In practice, grain scattering and distortion of clods on the spoil heap is likely to increase the proportion of exposed grains beyond the outermost layer.

Grave excavations are examples of anthropogenic sedimentation involving one bleaching cycle. While our observations of grave outline and infill structure are consistent with reconstructions based on ground penetrating radar (e.g. Gontz et al., 2011) the luminescence signature of grave sites is less easily identified. Our results suggest that, in cases where grave sites are subsequently buried by younger sediment, optical dating of the grave infill will yield the age of the sediments into which the grave was dug rather than the age of interment. In a stable landscape, age estimates will reflect ongoing bioturbation or mixing, 
including anthropogenic disturbance. While these conclusions are derived from two particular examples, OSL signatures may differ according to sediment age and type, depositional and weathering environment, and the relative difference between landform and burial age. Genuine investigations of grave digging must also consider the very real possibility that funerary ceremonies (or clandestine burials for that matter) were conducted at night. At the very least, we caution that future OSL investigations of grave infill, archaeological building materials, or indeed sediments from any depositional landform, should consider the potential bleaching effectiveness of the disturbance and depositional processes as well as the potential bleachability of the host sediment.

\section{Conclusions}

Experiments on mock graves in aeolian and fluvial sediments at two sites has shown that standard OSL procedures on single grains of quartz failed to correctly identify a dating signal related to grave digging and infill. Contrary to our expectations, inefficient bleaching during the excavation and backfilling process produced a small number of zero age grains that analytically are difficult to distinguish from contamination, bioturbation, or other causes of variation in $\mathrm{D}_{\mathrm{e}}$ values. Insufficient bleaching produced a reduction in the central age of $<16 \%$ and an increase in over-dispersion values of $5-10 \%$ compared to the undisturbed substrate. In older aeolian sediments, the bulk of infill retained the trapped OSL charge associated with the sediments into which the grave had been dug, and the Minimum Age Model overestimated the burial age by as much as 29,000 yr. A clearer disturbance signal was produced in younger fluvial sediments, but estimates of burial age from the minimum age model were too old by $120-400 \mathrm{yr}$. This suggests that, in some circumstances, the technique has insufficient accuracy for the archaeological or forensic analysis of ancient and recent grave sites. In other archaeological and geomorphological applications of OSL dating, we recommend routine checks on the effective zeroing of sediments in modern equivalent situations.

\section{Acknowledgements}


Thanks are due to Polly, may she rest in peace, and her fellow inhabitants of Garnpung Lodge: Michael Westaway, Tony Miscamble, Mark Collard, Duncan Wright, and to NSW National Parks and Wildlife for making the Lodge available. Ashneel Sharma assisted with the age modelling. Comments from two anonymous reviewers substantially improved the manuscript. This work was supported by ARC Linkage grant LP130160748 to the authors.

\section{References}

Aitken M.J., 1998: An Introduction to Optical Dating: The Dating of Quaternary Sediments by the use of Photon-stimulated Luminescence. Oxford University Press, Oxford: 276 pp.

Arnold, L.J., Roberts, R.G., Galbraith, R.F., DeLong, S.B., 2009. A revised burial dose estimation procedure for optical dating of young and modern-age sediments. Quaternary Geochronology 4, 306-325.

Ballarini, M., Wallinga, J., Wintle, A., Bos, A., 2007. Analysis of equivalent-dose distributions for single grains of quartz from modern deposits. Quaternary Geochronology 2, 77-82.

Beckers, B., Schütt, B., Tsukamoto, S., Frechen, M., 2013. Age determination of Petra's engineered landscape-optically stimulated luminescence (OSL) and radiocarbon ages of runoff terrace systems in the Eastern Highlands of Jordan. Journal of Archaeological Science 40, 333-348.

Berger, G.W., Post, S., Wenker, C., 2009. Single and multigrain quartz-luminescence dating of irrigation-channel features in Santa Fe, New Mexico. Geoarchaeology 24, 383-401.

Bowler, J. M., Johnston, H., Olley, J. M., Prescott, J. R., Roberts, R. G., Shawcross, W., and Spooner, N. A., 2003. New ages for human occupation and climate change at Lake Mungo, Australia. Nature 421, 837-840.

Bruno, D., Roberts, R.G., Magee, J., Mialenes, J., Turney, C., Bird, M., White, C., Fifield, L.K., Tibby, J., 2007. Sediment mixing at Nonda Rock: investigations of stratigraphic integrity at an early archaeological 
site in northern Australia and implications for the human colonisation of the continent. Journal of Quaternary Science 22, 449-479.

Duller, G.A.T., 2008. Single-grain optical dating of Quaternary sediments: why aliquot size matters in luminescence dating. Boreas 37, 589-612.

Feathers, J.K., Johnson, J., Kembel, S.R., 2008. Luminescence dating of monumental stone architecture at Chavín de Huántar, Perú. Journal of Archaeological Method and Theory 15, 266-296.

Fitzsimmons, K.E., Stern, N., Murray-Wallace, C.V., 2014. Depositional history and archaeology of the central Lake Mungo lunette, Willandra Lakes, southeast Australia. Journal of Archaeological Science $41,349-364$.

Galbraith, R.F., Laslett, G.M., 1993. Statistical models for mixed fission track ages. Nuclear Tracks and Radiation Measurements 21, 459-470.

Galbraith, R.F., Roberts, R.G., Laslett, G.M., Yoshida, H., Olley, J.M., 1999. Optical dating of single and multiple grains of quartz from Jimnium rock shelter, northern Australia: Part I. Experimental design and statistical models. Archaeometry 41, 339-364.

Galbraith, R.F., 2005. Statistics for Fission Track Analysis. Chapman \& Hall. CRC Press, Boca Raton.

Gontz, A.M., Maio, C.V., Berkland, E.P., Wagenknecht, E.K., 2011. Assessing threatened coastal sites: applications of ground-penetrating radar and geographic information systems. Journal of Cultural Heritage 12, 451-458.

Grün, R., Spooner, N., Magee, J., Thorne, A., Simpson, J., Yan, G., and Mortimer, G., 2011. Stratigraphy and chronology of the WHL 50 human remains, Willandra Lakes World Heritage Area, Australia. Journal of Human Evolution 60, 597-604.

Jacobs, Z., Duller, G.A.T., Wintle, A.G., 2006. Interpretation of single grain De distributions and calculation of De Radiation Measurements 41, 264-277. 
Jacobs, Z., Roberts, R. G., 2007. Advances in optically stimulated luminescence dating of individual grains of quartz from archaeological deposits. Evolutionary Anthropology 16, 210-223.

Johnston, H., Webb, S., Williams, D., 2003. Late Pleistocene burials from Garnpung Lake, Willandra Lakes Region World Heritage Area. Unpublished paper presented at the Australian Archaeological Association Conference, 4-7 December, 2003, Jindabyne.

Kemp, J., Rhodes, E., 2010. Episodic fluvial activity of inland rivers in southeastern Australia: Palaeochannel systems and terraces of the Lachlan River. Quaternary Science Reviews 29, 732-752.

Lomax, J., Hilgers, A., Twidale, C.R., Bourne, J.A., Radtke, U., 2007. Treatment of broad palaeodose distributions in OSL dating of dune sands from the western Murray Basin, South Australia. Quaternary Geochronology 2, 51-56.

Mejdahl, V., 1979. Thermoluminescence dating: beta-dose attenuation in quartz grains. Archaeometry 21, 6172.

Murray, A.S., Marten, R., Johnston, A., Martin, P., 1987. Analysis for naturally occurring radionuclides at environmental concentrations by gamma spectrometry. Journal of Radioanalytical and Nuclear Chemistry (Articles) 115, 263- 288.

Murray, A.S., Olley, J.M., 2002. Precision and accuracy in the optically stimulated luminescence dating of sedimentary quartz: a status review. Geochronometria: Journal on Methods and Applications of Absolute Chronology 21, 1-16.

Nathan, R.P., Thomas, P.J., Jain, M., Murray, A.S., Rhodes, E.J., 2003. Environmental dose rate heterogeneity of beta radiation and its implications for luminescence dating: Monte Carlo modelling and experimental validation. Radiation Measurements 37, 305-313.

Olley, J.M., Caitcheon, G.G., Roberts, R.G. 1999. The origin of dose distributions in fluvial sediments, and the prospect of dating single grains from fluvial deposits using optically stimulated luminescence. Radiation Measurements 30, 207-217. 
Olley, J.M., Pietsch, T., Roberts, R.G. 2004. Optical dating of Holocene sediments from a variety of geomorphic setting using single grains of quartz. Geomorphology 60, 337-358.

Olley, J.M., Roberts, R.G., Yoshida, H., Bowler, J.M., 2006. Single-grain optical dating of grave-infill associated with human burials at Lake Mungo, Australia. Quaternary Science Reviews 25, 2469-2474.

Pietsch, T.J., 2009. Optically stimulated luminescence dating of young ( $<500$ years old) sediments: testing estimates of burial dose. Quaternary Geochronology 4, 406-422.

Pietsch, T.J., Nanson, G.C., Olley, J.M. 2013. Late Quaternary changes in flow-regime on the Gwydir distributive fluvial system, southeastern Australia. Quaternary Science Reviews 69, 168-180.

Prescott, J.R., Hutton, J.T., 1994. Cosmic ray contributions to dose rates for luminescence and ESR dating: large depths and long term time variations. Radiation Measurements 23, 497-500.

Rhodes, E.J., Fanning, P.C., Holdaway, S.J., 2010. Developments in optically stimulated luminescence age control for geoarchaeological sediments and hearths in western New South Wales, Australia. Quaternary Geochronology 5, 348-352.

Roberts, H.M., Plater, A.J. 1999. U- and Th-series disequilibria in coastal infill sediments from Praia da Rocha (Algarve Region, Portugal): A contribution to the study of late Quaternary weathering and erosion. Geomorphology 26, 223-238.

Roberts, R.G., Galbraith, R.F., Yoshida, H., Laslett, G.M., Olley, J.M., 2000. Distinguishing dose populations in sediment mixtures: a test of single-grain optical dating procedures using mixtures of laboratorydosed quartz. Radiation Measurements 32, 459-465.

Sanjurjo-Sánchez, J., Mato, M.P., 2013. Delimiting the urban growth of Santiago de Compostela (NW Spain) by OSL dating of medieval anthropogenic sediments. Mediterranean Archaeology and Archaeometry $13,163-173$.

Sojka, R.E. 1999. Physical aspects of soils of disturbed ground. In: Walker, L.R. (Ed.) Ecosystems of Disturbed Ground, Elsevier, Amsterdam, 503-520. 
Stokes, S., Ingram, S., Aitken, M.J., Sirocko, F., Anderson, R., Leuschner, D., 2003. Alternative chronologies for Late Quaternary (Last Interglacial- Holocene) deep sea sediment via optical dating of silt-size quartz. Quaternary Science Reviews 22, 925- 941.

Thorne, A., Grün, R., Mortimer, G., Spooner, N.A., Simpson, J., McCulloch, M., Taylor, L., Curnoe, D., 1999. Australia's oldest human remains: age of the Lake Mungo 3 skeleton. Journal of Human Evolution 36, 591-612.

Webb, S.G., 1989. The Willandra Lakes Hominids. Department of Prehistory, Research School of Pacific Studies, Australian National University, Canberra.

Wintle A.G., 1997. Luminescence dating: laboratory procedures and protocols. Radiation Measurements 27: 769-817.

\section{Figure captions}

Figure 1. Photograph of the stratigraphic cross-section of Polly 1. The grave boundary is clearly evident (highlighted by the dashed line). The substrate is well sorted, red-brown medium sand. Black circles show the sampling locations. Sedimentary structures are also apparent within the grave infill as a result of differential drying of the spoil heap. The driest material, obtained from the top of the spoil heap, made up the lowermost infill material (being used first) whilst material used in the latter stages of grave closure was moist, having been obtained from the lowermost parts of the spoil heap.

Figure 2. a) The natural shine down curve (photon counts vs channel number) from a single grain of quartz from sample PGG17 and b) the associated growth curve.

Figure 3. Histograms of $\mathrm{D}_{\mathrm{e}}$ estimates from single grain of quartz from a) PGG25 - the burial substrate, b) PGG40 - grave infill at $40 \mathrm{~cm}$ depth and c) PGG17 - grave infill at $17 \mathrm{~cm}$ depth; d) shows the same data on a radial plot the closed symbols represent the data from the infill and the open symbols those from the substrate. Shaded area represents the best age estimate based on the minimum age model. 
Figure 4. Histograms of $D_{e}$ estimates from single grain of quartz from a) PGT25 - the burial substrate, and b) PGT40 - grave infill at 40 cm depth; c) shows the same data on a radial plot the closed symbols represent the data from the infill and the open symbols those from the substrate. Shaded area represents the best age estimate based on the minimum age model. 